\title{
Response to the Comment by the Board of the German IVF Register
}

\author{
Antwort auf den Kommentar des Vorstands des Deutschen IVF-Registers
}

Authors

Affiliation
S. Kadi, U. Wiesing

Institut für Ethik und Geschichte der Medizin, Eberhard Karls Universität Tübingen, Tübingen
Deutsche Version unter: http://dx.doi.org/ $10.1055 / \mathrm{s}-0042-108897$

Bibliography

Dol http://dx.doi.org/

$10.1055 / \mathrm{s}-0042-108897$

Geburtsh Frauenheilk 2016; 76: 688-689 ๑ Georg Thieme Verlag KG Stuttgart · New York . ISSN 0016-5751

\section{Correspondence}

\section{Dr. Selma Kadi}

Institut für Ethik und Geschichte der Medizin

Eberhard Karls Universität

Gartenstraße 47

72074 Tübingen

selma.kadi@uni-tuebingen.de
1. We welcome the fact that the Board of the D.I.R rated 4 of the 5 criticisms as "not altogether wrong" and repeatedly indicated that our criticism was justified ("Kadi and Wiesing pointed out [...] rightly..."). That the Board has again stated that the approach of the D.I.R is "considered exemplary, also by international standards" surprised us.

2. Number of participting centers: When the Board of the D.I.R says that "[o]ut of a total of 132 IVF centers known to us in Germany, 131 centers (99.2\%) are members of the D.I.R", this simply reveals the extent of the crisis. How many centers are not known to the Board of the D.I.R? Does the D.I.R have a basis which allows them to be sure they are aware of all the centers?

3. Prospective data entry: The Board of the D.I.R vehemently rejects our statement that "it cannot be precluded that all data is only entered after some delay" which would mask retrospectively entered data as prospectively entered data. One of the anonymous reviewers pointed out this possibility of manipulation to us: "At present, the prospective entry of data is controlled by the necessity of entering the start of stimulation before entering the 'successful outcome', i.e. hCG positivity. But this does not preclude the possibility, for example, that cycles may not be entered at all or that they are entered at a later point in time, so that the start of stimulation along with the entire cycle is only entered after the fact. The authors (Kadi/ Wiesing) are therefore right to demand that the entry of data should be controlled" (quoted from the reviewer's report). Instead of "strongly" repudiating this possibility, the D.I.R should be able to effectively rule out this manipulation - which it is currently unable to do.

4. Reference to the D.I.R guideline: The Board of the D.I.R rightly points out that responsibility lies with the respective medical associations of the different federal states. But federalism in the Federal Republic of Germany has never been a convincing argument for poor scientific documentation. A discipline which purports to be scientific (and reproductive medicine should be one of them!) cannot invoke federal responsibility if it does not meet its own documentation standards.

5. The publication of center-specific data: The Board of the D.I.R has spoken out against the publication of center-specific data and refers patients instead to doctor-patient discussions. Nevertheless: the two are not mutually exclusive! What is wrong with having a doctor-patient discussion where the patient already has high-quality comprehensible information about the center at the start of the discussion? There can surely be no doubt that such a discussion with the doctor is likely to go better. Regrettably, the necessary conditions for this to happen do not currently exist in Germany. At the moment, even if they go to the trouble of researching on the internet, patients will only be able to find detailed information on a center's own birth rates for a very limited number of centers [1]. If a center excludes patients with a poor prognosis, then this would have to be indicated when reporting on the center's success rates. Centers would have to disclose which indications they accept and which ones they don't.

6. Comprehensible information for patients: The Board of the D.I.R has pointed out that in previous years it issued summaries suitable for patients. One cannot expect potential patients to carry out historical searches and work their way through previous annual reports, particularly as the data are no longer up-to-date. This was the only one of our 5 criticisms which the Board considered to be unjustified. But its statement that the last summary was primarily intended for journalists confirms our criticism. 
And so there is no up-to-date summary especially intended for patients! Fortunately the Board has announced that it has taken this criticism on board and that it will publish up-to-date information in a form comprehensible to non-specialists in the next annual report.

\section{Conflict of Interest}

None.

\section{References}

1 Kadi S, Wiesing $U$. Uninformed Decisions? The Online Presentation of Success and Failure of IVF and Related Methods on German IVF Centre Websites. Geburtsh Frauenheilk 2015; 75: 1258-1263 